\title{
Supramolecular medicinal chemistry: mixed-ligand pharmaceutical coordination complexes
}

\author{
Zhenbo Ma and Brian Moulton* \\ Dept of Chemistry, Brown University, 324 Brook St, Providence, RI 02912, USA.
}

Title Running Head: Mixed-ligand pharmaceutical metal complexes

* To whom correspondence should be addressed. Phone 401-863-3775. Fax 401-863-9046. E-mail: brian_moulton@brown.edu. 


\section{ESI-MS}

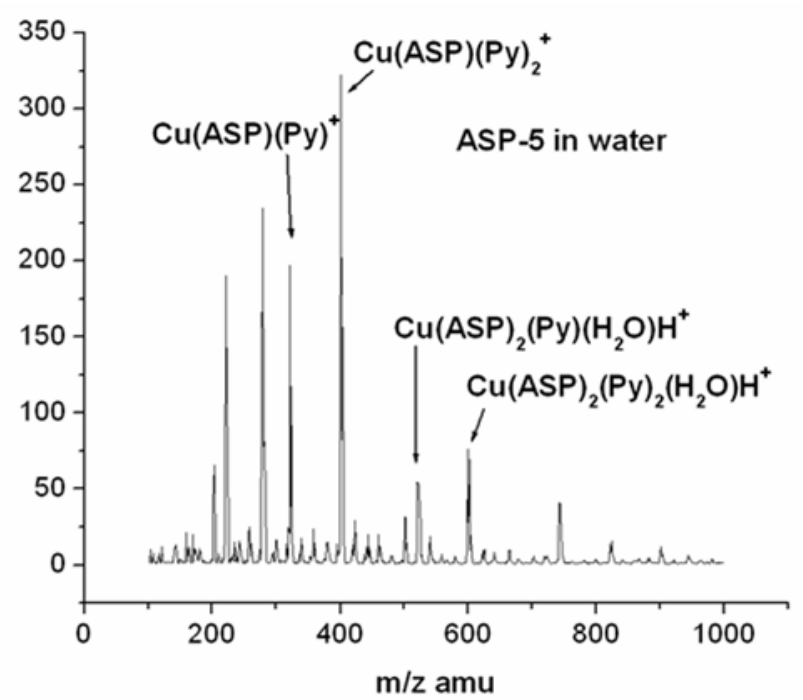

Figure S1. ESI-MS for ASP-5 in water.

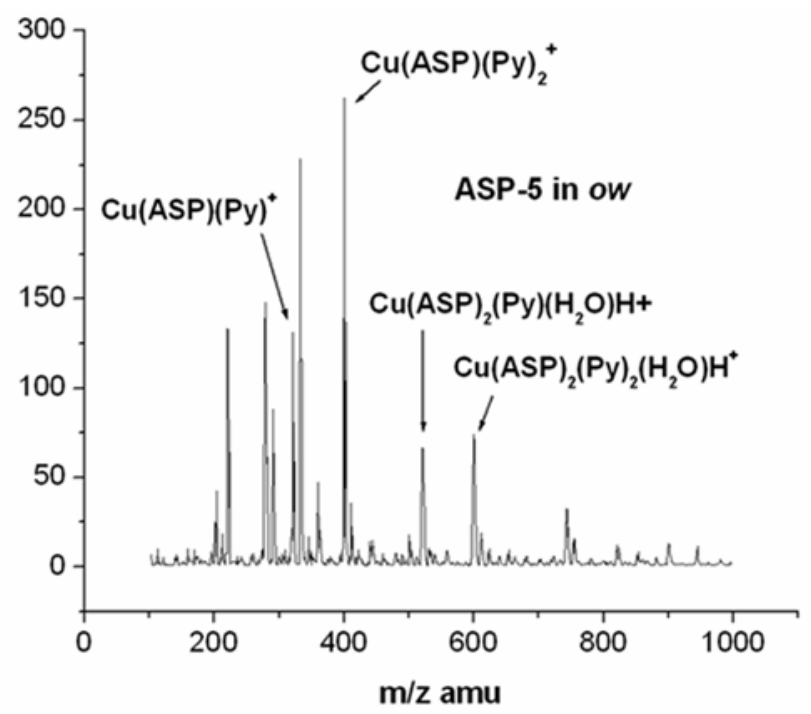

Figure S2. ESI-MS for ASP-5 in octanol saturated water.

The electrospray ionization mass spectra of ASP-5 in water and octanol saturated water are shown in Figure S1 \& S2 respectively. The spectra show that ASP-5 exists in aqueous solution as a monomer $\left(\mathrm{Cu}(\mathrm{ASP})_{2}(\mathrm{Py})_{2}\left(\mathrm{H}_{2} \mathrm{O}\right) \mathrm{H}^{+}, \quad \mathrm{m} / \mathrm{z} \quad\right.$ 598.7; $\mathrm{Cu}(\mathrm{ASP})_{2}(\mathrm{Py})\left(\mathrm{H}_{2} \mathrm{O}\right) \mathrm{H}^{+}, \mathrm{m} / \mathrm{z}$ 519.7; Cu(ASP)(Py $)_{2}{ }^{+}, \mathrm{m} / \mathrm{z}$ 399.8; $\mathrm{Cu}(\mathrm{ASP})(\mathrm{Py})^{+}, \mathrm{m} / \mathrm{z}$ 320.8). The fragmentation of ASP-5 should result from the electrospray ionization. 
These masses indicate the formation of a monohydrate speicies of ASP-5, $\mathrm{Cu}(\mathrm{ASP})_{2}(\mathrm{AL})_{2}\left(\mathrm{H}_{2} \mathrm{O}\right)$. The formation of $\mathrm{Cu}(\mathrm{ASP})_{2}(\mathrm{AL})_{2}\left(\mathrm{H}_{2} \mathrm{O}\right)$ is also observed by us from the ESI-MS of ASP-7 and ASP-8 in aqueous solution. Indeed, for mononuclear $\mathrm{Cu}(\mathrm{II})$ species, the coordination of anionic API and neutral AL to copper in solution has been confirmed by the mass spectra. 


\section{DOSY}

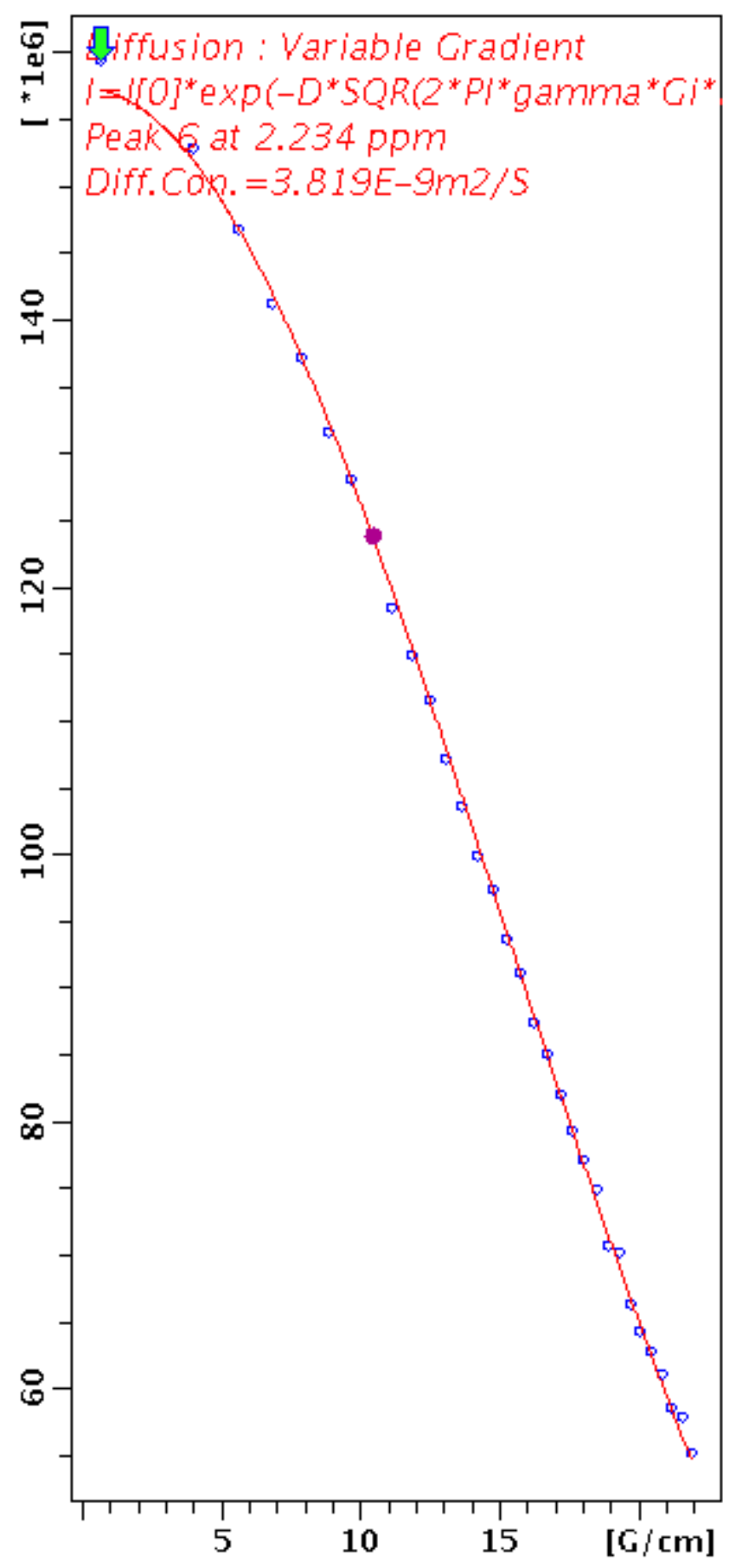

Figure S3. Determination of diffusion coefficients for ASP-3 ( $\left.\mathrm{Cu}_{2}(\mathrm{ASP})_{4}(3-\mathrm{Br}-\mathrm{Py})_{2}\right)$ in $\mathrm{D}_{2} \mathrm{O}$. Representative plots of peak intensity against gradient strength was fitted to an exponential decay using the Simfit program within Bruker Topspin software. Since ASP \& 3-Br-Py was determined to be in one species in aqueous phase, only the diffusion coefficient of the peak at 2.234 ppm was shown here. 


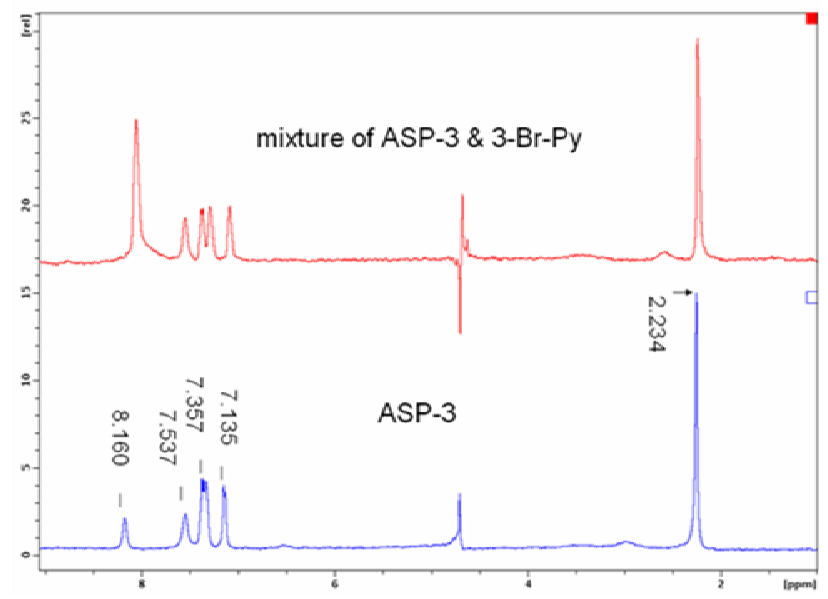

Figure S4. ${ }^{1} \mathrm{H}$ NMR spectra of ASP-3 and ASP-3/3-Br-Py mixture in $\mathrm{D}_{2} \mathrm{O}$.

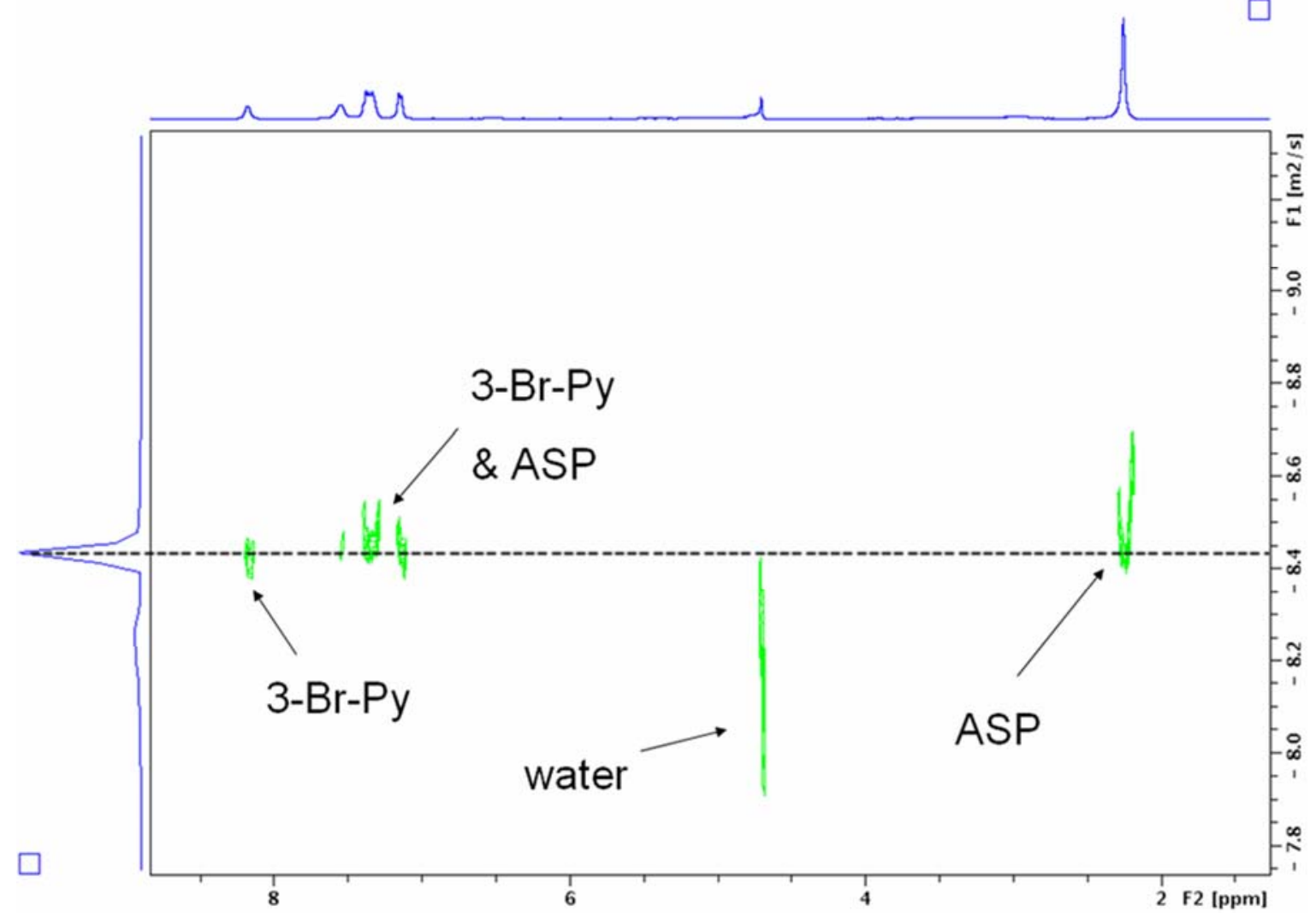

Figure S5. ${ }^{1} \mathrm{H}$ DOSY spectrum of ASP-3 in $\mathrm{D}_{2} \mathrm{O}$.

Since structures of binuclear $\mathrm{Cu}(\mathrm{II})$ complexes are analogous, as a model, ASP-3 was investigated by using NMR diffusion measurement for stability studies. Diffusion-Ordered Spectroscopy (DOSY) methods are based on pulsed-field gradient 
spin-echo NMR experiments. In particular, DOSY is effective to analyze intermediate and to discriminate the different species in solution. Figure S4 shows the ${ }^{1} \mathrm{H}$ NMR spectra obtained for ASP-3 and the mixture after a small amount of 3-Br-Py has been added. The spectra shows a complicated pattern because of the existence of paramagnetic $\mathrm{Cu}(\mathrm{II})$ in solution. The sharp peak at $2.234 \mathrm{ppm}$ is due to the aspirin methyl groups. The small peak on the left at $8.160 \mathrm{ppm}$ is assigned to one proton of 3-Br-Py by comparing the ${ }^{1} \mathrm{H}$ NMR spectra of ASP-3 and ASP-3/3-Br-Py mixture. Peaks in the range of 7-8 ppm are due to the peak overstacking of aspirin and 3-Br-Py aromatic protons. A DOSY experiment was performed on a solution of ASP-3 in $\mathrm{D}_{2} \mathrm{O}$, Figure S5. The resulting ${ }^{1} \mathrm{H}$ NMR DOSY spectrum nicely suggests that aspirin anion and 3-Br-Py belongs to one species in water based on the diffusion coefficient. The diffusion coefficient for ASP-3 was $3.819 \times 10^{-9} \mathrm{~m}^{2} / \mathrm{s}$. This result indicates the homogeneity of ASP-3 in solution. Although no further determination of the configuration of ASP-3 in solution was undertaken in this study, it is clear from the DOSY spectrum the dissociation of mixed ligand $\mathrm{Cu}$ species in aqueous phase is insignificant. 